\title{
Plasma Polymerization of Hexamethyldisilazane
}

\author{
Soo Young PARK, Nakjoong KIM, Un Young KIM, \\ Sung Il HONG, ${ }^{*}$ and Hiroyuki SASABE** \\ Polymer Chemistry Laboratory, Korea Institute of Science and \\ Technology, Cheong-Ryang P.O. Box 131, Seoul, Korea \\ * Department of Textile Engineering, Seoul National University, \\ Shin-Lim Dong San 56-1, Kwan-Ak Ku, Seoul, Korea \\ ** Biopolymer Physics Laboratory, The Institute of Physical and \\ Chemical Research (RIKEN), Wako, Saitama 351-01, Japan
}

(Received October 11, 1989)

\begin{abstract}
The chemical structure, density, and deposition rate of hexamethyldisilazane plasma polymer were investigated in terms of reaction conditions, such as discharge power $(W)$ and mass flow rate $\left(F_{\mathrm{m}}\right)$. The importance of the specific energy per mass $\left(W / F_{\mathrm{m}}\right)$ as the major controlling parameter of plasma polymerization was confirmed in this study. A notable influence of $W / F_{\mathrm{m}}$ on the chemical structure corresponded with the changes in density and deposition yield of plasma polymer. Deposition rate equation was proposed from the simplified model of plasma polymerization. Regression analysis of the experimental data supported the equation.

KEY WORDS Plasma Polymerization / Organosilicon / Hexamethyldisilazane / FTIR / Density / Deposition Rate /
\end{abstract}

The formation of thin organic films by the plasma polymerization has received considerable attention due to the excellent physical and chemical properties of those thin films. ${ }^{1,2}$ Great research efforts have accumulated with respect to the practical applications including the electronic ${ }^{3-8}$ or optical ${ }^{9-12}$ devices, separation membranes, ${ }^{13,14}$ protective coatings, ${ }^{15}$ and biomedical materials. ${ }^{16}$ Therefore, selective and reproducible controls of (i) the chemical structure and related physical properties and (ii) the film deposition rate are more strictly required for the practical application of plasma polymer film.

Differing from the conventional polymeric materials, the chemical structure of plasma polymer is controlled by the operational parameters even when the same monomer and reactor are used for the plasma polymerization reactions. ${ }^{1}$ Among the numerous operational parameters, ${ }^{1,2}$ the effects of discharge power $(W)$ and mass flow rate $\left(F_{\mathrm{m}}\right)$ on the chemical structure of plasma polymer have been studied by many investigators. ${ }^{1,17-20}$ Generally, it was found that the higher value of $W$ or the lower value of $F_{\mathrm{m}}$ resulted in the more tightly crosslinked chemical structure of plasma polymer. To explain these structural observations, Yasuda and Hirotsu ${ }^{21}$ proposed the composite parameter $W / F_{\mathrm{m}}$ as the major parameter of structure control. Because $W$ is the rate of energy supply and $F_{\mathrm{m}}$ is the rate of monomer supply to the plasma reactor, $W / F_{\mathrm{m}}$ represents the average energy delivered to the unit mass of monomer in a discharge state. Therefore, the chemical structure and related physical properties of plasma polymer are expected to be uniquely controlled by this $W / F_{\mathrm{m}}$ parameter.

The effect of operational parameters on the deposition rate of plasma polymer draws attention in two aspects. Practical interest concerns the exact thickness control of the plasma polymer film. Academic interest issues from 
the hope that the detailed study on the deposition kinetics will assist in understanding the extremely complex process of plasma reaction. Although many investigators have been engaged in this study, $, 2,20,22-25$ experimental results are yet insufficient to understand the basic mechanism of plasma polymerization.

In the present work, we investigated the effect of operational parameters $W$ and $F_{\mathrm{m}}$ on the chemical structure, density, and deposition rate of hexamethyldisilazane (HMDSIZ) plasma polymer for the selective and reproducible control of them and also for the clear understanding of the nature of plasma polymerization.

\section{EXPERIMENTAL}

\section{Plasma Polymerization}

A schematic diagram of the plasma reactor is shown in Figure 1. It consists of a Pyrex bell-jar with the internal discharge electrodes. The RF (13.56 MHz) power was capacitively

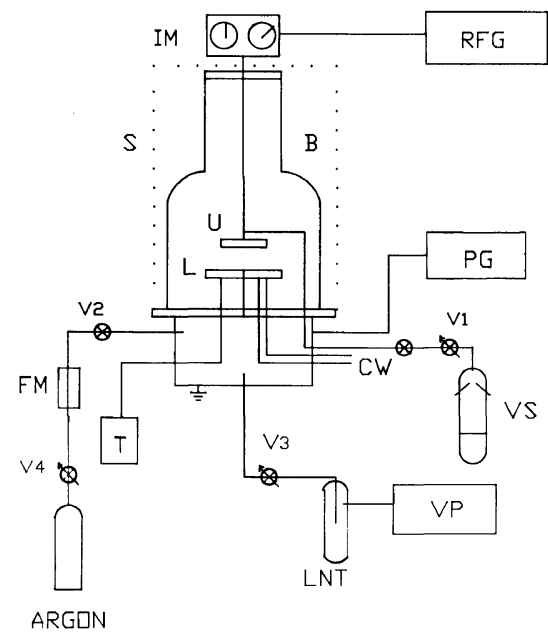

Figure 1. Schematic diagram of plasma polymerization reactor: (RFG) RF generator; (IM) impedance matching circuit; (B) bell-jar; (S) RF shield; (PG) pressure gauge; (U) upper electrode, powered; (L) lower electrode, grounded; (VS) monomer reservoir; $\left(\mathrm{V}_{1}\right)$ micro metering valve; $\left(\mathrm{V}_{3}\right)$ throttle valve; $(\mathrm{CW})$ cooling water; (FM) flow meter; (T) thermocouple and heater; (LNT) liquid nitrogen trap; (VP) vacuum pump. coupled to the plasma reactor through the impedance matching circuit.

Prior to the electric discharge, HMDSIZ monomer was charged into the Pyrex reservoir (VS), and degassed by the freeze-thaw method.

The whole system was initially evacuated down to $10^{-3}$ Torr using a mechanical vacuum pump (Edwards, model E2M-18). The system pressure was monitored by a Pirani vacuum gauge without a specific calibration for the HMDSIZ vapor. The monomer vapor was introduced into the reactor from the down-side holes of upper electrode, keeping the downstream throttle valve $\left(\mathrm{V}_{3}\right)$ fully open throughout the experiments. Thus, the flow rate of monomer and system pressure were controlled simultaneously using a micro metering valve $\left(\mathrm{V}_{1}\right.$, Nupro SS-4BMG). The mass flow rate $\left(F_{\mathrm{m}}\right)$ was determined by cutting off the vacuum pump and monitoring the initial increase of system pressure with time. ${ }^{1}$ Following the stabilization of $F_{\mathrm{m}}$, glow discharge was initiated and continued over $20 \mathrm{~min}$ at the fixed discharge power $(W)$. During the glow discharge, the substrate on the lower electrode was cooled by the tap water.

\section{Chemical Structure}

Effects of $W$ and $F_{\mathrm{m}}$ on the chemical structure were investigated by the IR absorption spectra of plasma polymer. HMDSIZ plasma polymer was deposited on the aluminum foil, and the absorption spectra were taken by the external reflection method ${ }^{26}$ using a Mattson FTIR spectrophotometer.

\section{Density}

Density gradient column (Techne, Model DC-1) was used for the density measurement of plasma polymer scraped from the lower electrode: ethanol/carbontetrachloride column for $0.79-1.59 \mathrm{~g} \mathrm{~cm}^{-3}$, and carbontetrachloride/ bromoform column for $1.60-2.89 \mathrm{~g} \mathrm{~cm}^{-3}$.

\section{Deposition Rate}

A pair of slide glasses (Clay Adams, No 
3058) masked with thin cover slips were used as the substrate on the lower electrode. After the deposition of plasma polymer, the stepheights at the six radial positions were measured using a Talysurf 10 (Taylor-Hobbson). The average deposition rate $\left(D R: \AA \mathrm{min}^{-1}\right)$ was calculated from these local deposition rates (step-heights/deposition time). The mass deposition rate $\left(D R_{\mathrm{m}}\right)$ was then calculated from $D R$ and the evaluated density at each $W$, $F_{\mathrm{m}}$ conditions.

\section{RESULTS AND DISCUSSION}

Plasma polymerization of organosilicon compounds has been widely investigated due to the excellent thermal, ${ }^{27}$ electrical, ${ }^{28}$ optical, ${ }^{11}$ and biomedical ${ }^{16}$ properties of the plas-
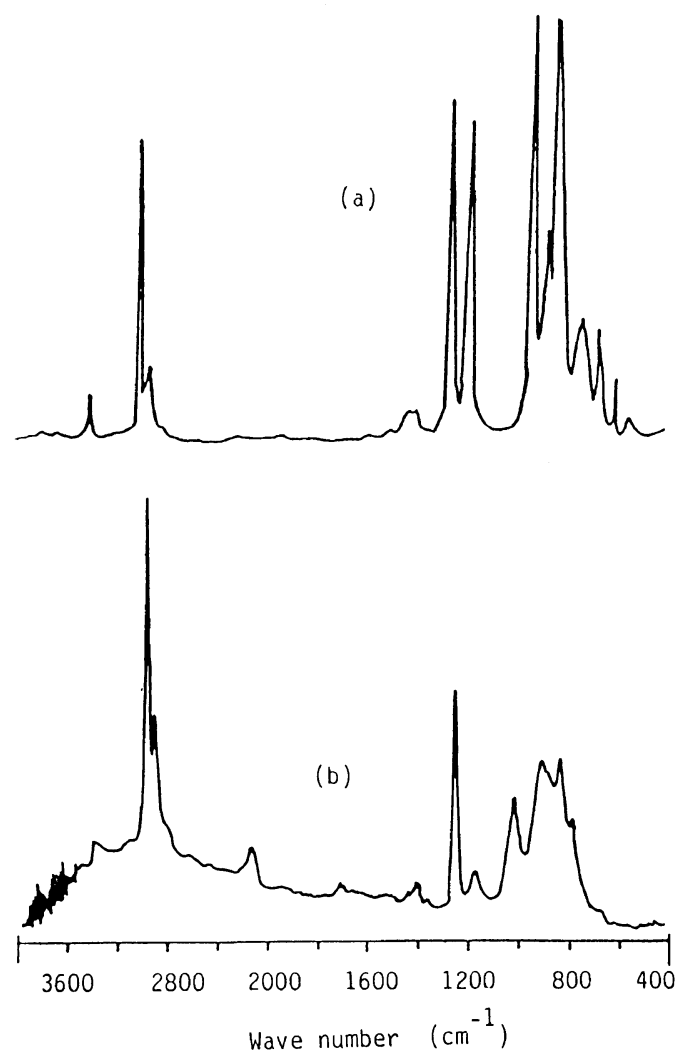

Figure 2. IR absorption spectra of (a) HMDSIZ monomer and (b) HMDSIZ plasma polymer $\left(W / F_{\mathrm{m}}=\right.$ $20.8 \mathrm{MJ} \mathrm{kg}^{-1}$ ). ma polymerized film. HMDSIZ, one of the commonly used monomer, ${ }^{1,11,16,27-29}$ was chosen in this study because the chemical structure and physical properties of the plasma polymer were expected to well-correlate with the operational parameters due to the $\mathrm{Si}$ and $\mathrm{N}$ containing chemical structure of monomer molecule. $^{28}$

Figure 2 compares the IR absorption spectrum of HMDSIZ monomer with that of plasma polymer $\left(W / F_{\mathrm{m}}=20.8 \mathrm{MJ} \mathrm{kg}^{-1}\right)$. The monomer spectrum was identified by the absorption bands of $\mathrm{Si}-\mathrm{CH}_{3}, \mathrm{Si}-\mathrm{N}-\mathrm{Si}$, and $\mathrm{N}-\mathrm{H}$

Table I. Band assignments of FTIR spectra

\begin{tabular}{|c|c|c|}
\hline Material & $\frac{\text { Peak position }}{\mathrm{cm}^{-1}}$ & Assignments ${ }^{30-32}$ \\
\hline $\begin{array}{l}\text { HMDSIZ } \\
\text { monomer }\end{array}$ & $\begin{array}{r}3381 \\
2956 \\
2898 \\
1400 \\
1254 \\
1182 \\
934 \\
851,842 \\
755-618\end{array}$ & $\begin{array}{l}v(\mathrm{~N}-\mathrm{H}) \\
v_{\mathrm{a}}(\mathrm{C}-\mathrm{H}) \text { in } \mathrm{Si}-\mathrm{CH}_{3} \\
v_{\mathrm{s}}(\mathrm{C}-\mathrm{H}) \text { in } \mathrm{CH}_{3} \\
\delta_{\mathrm{a}}\left(\mathrm{CH}_{3}\right) \text { in } \mathrm{Si}-\mathrm{CH}_{3} \\
\delta_{\mathrm{s}}\left(\mathrm{CH}_{3}\right) \text { in } \mathrm{Si}-\mathrm{CH}_{3} \\
\delta(\mathrm{N}-\mathrm{H}) \\
v_{\mathrm{a}}(\mathrm{Si}-\mathrm{N}-\mathrm{Si}) \\
\rho\left(\mathrm{CH}_{3}\right) \text { in } \mathrm{Si}-\left(\mathrm{CH}_{3}\right)_{3} \\
v(\mathrm{Si}-\mathrm{C})\end{array}$ \\
\hline $\begin{array}{l}\text { HMDSIZ } \\
\text { plasma } \\
\text { polymer }\end{array}$ & $\begin{array}{r}* 3400 \\
3370 \\
2956 \\
* 2928 \\
2902 \\
* 2856 \\
* 2125 \\
* 1705 \\
* 1430 \\
1400 \\
* 1350 \\
1254 \\
1180 \\
* 1100-1000 \\
* 1030 \\
920-900 \\
840 \\
* 792 \\
900-500\end{array}$ & $\begin{array}{l}v(\mathrm{O}-\mathrm{H}) \\
v(\mathrm{~N}-\mathrm{H}) \\
v_{\mathrm{a}}(\mathrm{C}-\mathrm{H}) \text { in } \mathrm{CH}_{3} \\
v_{\mathrm{a}}(\mathrm{C}-\mathrm{H}) \text { in } \mathrm{CH}_{2} \\
v_{\mathrm{s}}(\mathrm{C}-\mathrm{H}) \text { in } \mathrm{CH}_{3} \\
v_{\mathrm{s}}(\mathrm{C}-\mathrm{H}) \text { in } \mathrm{CH}_{2} \\
v(\mathrm{Si}-\mathrm{H}) \\
v(\mathrm{C}=\mathrm{O}) \\
\delta_{\mathrm{a}}\left(\mathrm{CH}_{2}\right) \text { in } \mathrm{Si}-\mathrm{CH}_{2}-\mathrm{CH}_{2}-\mathrm{Si} \\
\delta_{\mathrm{a}}\left(\mathrm{CH}_{3}\right) \\
\delta_{\mathrm{a}}\left(\mathrm{CH}_{2}\right) \text { in } \mathrm{Si}-\mathrm{CH}_{2}-\mathrm{Si} \\
\delta_{\mathrm{s}}\left(\mathrm{CH}_{3}\right) \text { in } \mathrm{Si}-\mathrm{CH}_{3} \\
\delta(\mathrm{N}-\mathrm{H}) \\
v_{\mathrm{a}}(\mathrm{Si}-\mathrm{O}-\mathrm{Si}), v_{\mathrm{a}}\left(\mathrm{Si}_{-} \mathrm{O}-\mathrm{C}\right) \\
\omega\left(\mathrm{CH}_{2}\right) \text { in } \mathrm{Si}-\left(\mathrm{CH}_{2}\right)_{n}-\mathrm{Si} \\
v_{\mathrm{a}}(\mathrm{Si}-\mathrm{N}-\mathrm{Si}) \\
\rho\left(\mathrm{CH}_{3}\right) \text { in } \mathrm{Si}-\left(\mathrm{CH}_{3}\right)_{n}, n=2,3 \\
\rho(\mathrm{CH}) \text { in } \mathrm{Si}-\left(\mathrm{CH}_{3}\right)_{n}, n=1,2 \\
v(\mathrm{Si}-\mathrm{C})\end{array}$ \\
\hline
\end{tabular}

$(*)$ peaks absent in the monomer spectrum, $(v)$ stretching, $(\delta)$ bending, $(\rho)$ rocking, $(\omega)$ wagging, $\left({ }_{a}\right)$ asymmetric mode, $\left(_{\mathrm{s}}\right)$ symmetric mode. 
bonds as shown in Table I. The absorption bands of plasma polymer differ from those of monomer, and can be summarized as follows: (i) The absorption intensity of $\mathrm{Si}-\mathrm{CH}_{3}$ group $\left(1254,2956 \mathrm{~cm}^{-1}\right)$ reduced, and new absorption bands of $\mathrm{Si}-\mathrm{CH}_{2}-\mathrm{Si}$ or $\mathrm{Si}-\mathrm{CH}_{2}-\mathrm{CH}_{2}-\mathrm{Si}$ group $\left(2928,1430,1350,1030,790 \mathrm{~cm}^{-1}\right)$ appeared; (ii) The absorption band of $\mathrm{Si}-\mathrm{H}$ stretching $\left(2125 \mathrm{~cm}^{-1}\right)$ newly appeared; (iii) The absorption intensity of $\mathrm{N}-\mathrm{H}$ group (3381, $1182 \mathrm{~cm}^{-2}$ ) reduced, and the absorption band of $\mathrm{Si}-\mathrm{N}-\mathrm{Si}$ stretching $\left(934 \mathrm{~cm}^{-1}\right)$ broadened; (iv) The new absorption bands due to the probably oxidized structure appeared, such as $\mathrm{O}-\mathrm{H}\left(3400 \mathrm{~cm}^{-1}\right), \mathrm{C}=\mathrm{O}\left(1705 \mathrm{~cm}^{-1}\right)$, and $\mathrm{Si}-$ O-Si $\left(1100-1000 \mathrm{~cm}^{-1}\right)$.

Although the plasma polymerization is conceived as an extremely complex process, it is generally agreed that the monomer molecules introduced into plasma are activated into reactive fragments, which then recombine to form a new chemical bond. ${ }^{1,20}$ The repetition of these activation and mutual recombination reaction of monomer molecules in a plasma leads to the deposition of plasma polymer which possesses a randomly cross-linked network structure. Thus, the chemical structure of plasma polymer is primarily controlled by the fragmentation pattern in a discharge state. ${ }^{33}$ Because the fragmentation of a molecule in a plasma should be related to the specific energy received per unit molecule the control of chemical structure by the $W / F_{\mathrm{m}}$ parameter is well-understood. ${ }^{21}$ The structural observations (i) - (iv) of HMDSIZ plasma polymer suggest that the activation reaction possibly occurs by the fragmentation of $\mathrm{Si}-\mathrm{C}, \mathrm{C}-\mathrm{H}$, and $\mathrm{N}-\mathrm{H}$ bonds, which is not unexpected in a discharge state.

To evaluate the $W / F_{\mathrm{m}}$ parameter and its effect on chemical structure, FTIR spectra of HMDSIZ plasma polymers were compared in terms of the cautiously controlled $W$ and $F_{\mathrm{m}}$. Figure 3(A) shows the effect of $W$ at a fixed $F_{\mathrm{m}}$, and Figure 3(B) shows the effect of $F_{\mathrm{m}}$ at a fixed $W$. It can be seen that the structural changes by increasing $W(\mathrm{a} \rightarrow \mathrm{b} \rightarrow \mathrm{c})$ correspond to those by decreasing $F_{\mathrm{m}}(\mathrm{d} \rightarrow \mathrm{e} \rightarrow \mathrm{f})$. Moreover, comparing the spectra of a with $d$, and b with $\mathrm{e}$, it can be proved that the magnitude of $W / F_{\mathrm{m}}$ regardless of their individual $W$ and $F_{\mathrm{m}}$ values is responsible for the control of chemical structure. The distinguished spectral change with increasing $W / F_{\mathrm{m}}$ was the gradual reduction of absorption intensities of $\mathrm{Si}-\mathrm{CH}_{3}\left(1254,2956 \mathrm{~cm}^{-1}\right)$, accompanying the increased absorption intensities of $\mathrm{Si}-\mathrm{CH}_{2}-\mathrm{Si}$ or $\mathrm{Si}-\mathrm{CH}_{2}-\mathrm{CH}_{2}-\mathrm{Si}(2928$, $\left.1030 \mathrm{~cm}^{-1}\right)$. The reduction of absorption intensity due to $\mathrm{N}-\mathrm{H}\left(1182 \mathrm{~cm}^{-1}\right)$ and broadening of absorption bands in the 1100 $600 \mathrm{~cm}^{-1}$, which represent the complex chemical structure with enhanced inorganic character, ${ }^{34}$ were also observed with increasing $W /$ $F_{\mathrm{m}}$. Therefore, all the structural observations of HMDSIZ plasma polymer suggest that the higher value of $W / F_{\mathrm{m}}$ probably corresponds with the more severe fragmentation (activation) per monomer molecule in a discharge state, and consequently with the more tightly cross-linked network structure of plasma polymer.

Figure 4 shows the effect of $W / F_{\mathrm{m}}$ on the density of HMDSIZ plasma polymer. With increasing $W / F_{\mathrm{m}}$, gradual increase of density was observed, which accorded with the changes of chemical structure monitored by IR absorption (Figure 3). The density of plasma polymer at the lower $W / F_{\mathrm{m}}$ is not much different from that of organosilicon polymer: polydimethylsiloxane, $0.98 \mathrm{~g} \mathrm{~cm}^{-3}$. However, with increasing $W / F_{\mathrm{m}}$, the density gradually increases and approximates that of inorganic covalent materials (higher than $2.0 \mathrm{~g} \mathrm{~cm}^{-3}$ ): ${ }^{35}$ such as silicon nitride, or silicon carbide. In this respect, Yasuda distinguished the plasma polymer from both the "polymeric" and "inorganic" material. ${ }^{1}$ He classified plasma polymer as belonging to the new material category which lies somewhere between the polymeric and inorganic category. ${ }^{1}$ This means that unique material properties so far not 
S. Y. PARK et al.

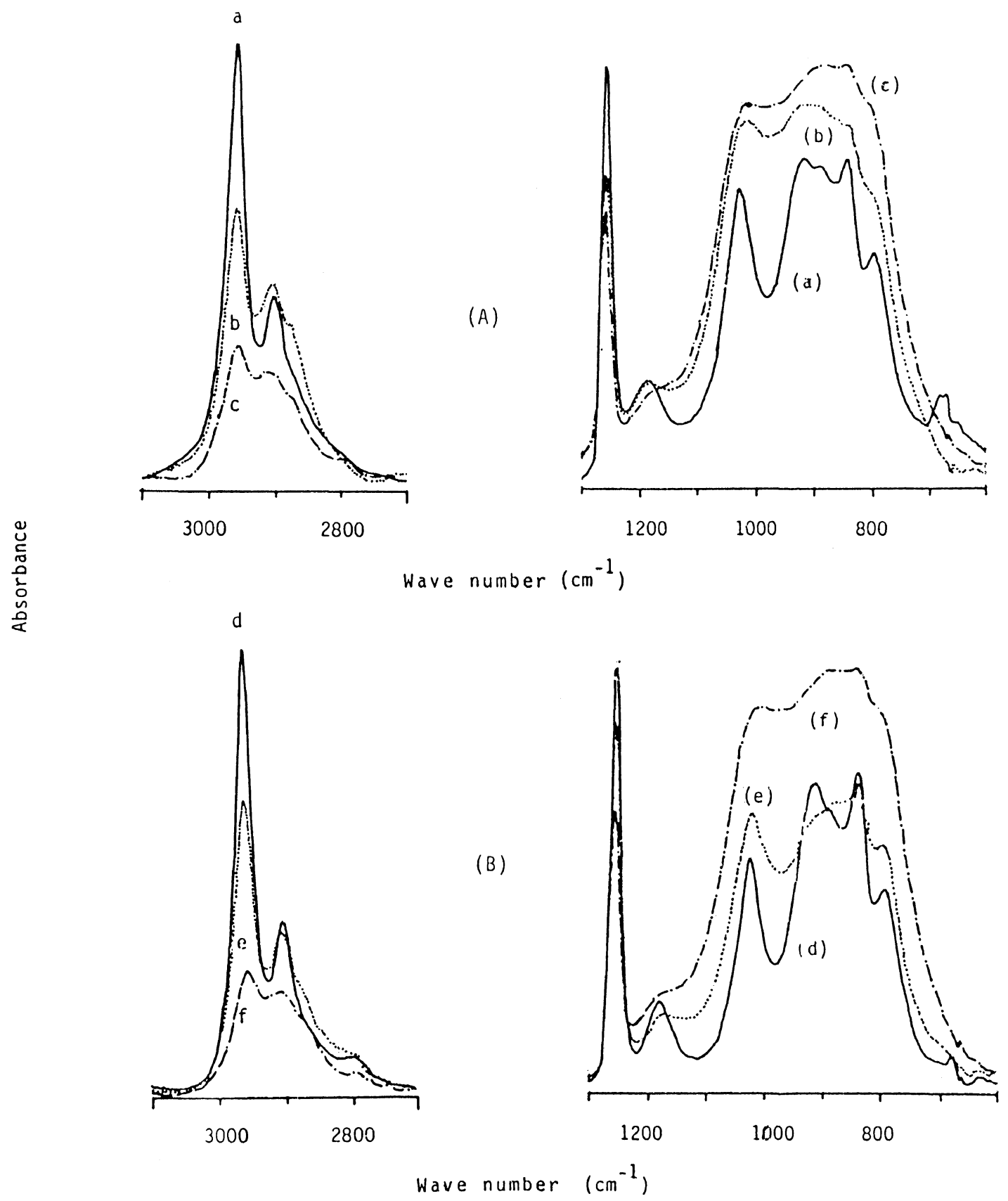

Figure 3. Effects of $W$ and $F_{\mathrm{m}}$ on the IR absorption spectra of HMDSIZ plasma polymer:

\begin{tabular}{|c|c|c|c|c|c|c|c|}
\hline \multirow{2}{*}{ (A) } & $w$ & $F_{\mathrm{m}}$ & $W / F_{\mathrm{m}}$ & \multirow{2}{*}{ (B) } & $W$ & $F_{\mathrm{m}}$ & $W / F_{\mathrm{m}}$ \\
\hline & watts & $\mathrm{mg} \mathrm{min}^{-1}$ & $\mathrm{MJ} \mathrm{kg}^{-1}$ & & watts & $\mathrm{mg} \min ^{-1}$ & $\mathrm{MJ} \mathrm{kg}^{-1}$ \\
\hline a & 10 & 23.9 & 25.2 & d & 50 & 144.1 & 20.8 \\
\hline b & 30 & 23.9 & 75.5 & e & 50 & 50.2 & 59.8 \\
\hline c & 50 & 23.9 & 125.8 & f & 50 & 23.9 & 125.8 \\
\hline
\end{tabular}


obtainable with polymeric or inorganic material can now be obtained by the plasma polymerization method. Moreover, selective control of properties is possible by the proper choice of operational parameter $W / F_{\mathrm{m}}$ as shown in Figure 4.

It has been confirmed that the chemical structure and density of plasma polymer are controlled by the specific energy per mass of molecule $W / F_{\mathrm{m}}$. However, the deposition rate $\left(D R_{\mathrm{m}}\right)$ is not expected to hold the same relation to $W / F_{\mathrm{m}}{ }^{1}$ because the $D R_{\mathrm{m}}$ is controlled not only by the degree of activation per molecule (controlled by $W / F_{\mathrm{m}}$ ), but also by the total supply rate of molecules into the reactor $\left(F_{\mathrm{m}}\right)$. Therefore, Gazicki and Yasuda ${ }^{36}$ proposed a correlation of the yield of deposition $\left(D R_{\mathrm{m}} / F_{\mathrm{m}}\right)$ with $W / F_{\mathrm{m}}$, instead of using $D R_{\mathrm{m}}$ itself. Because the deposition of plasma polymer proceeds through the repeated reaction of activation and mutual recombination, the activation (fragmentation) steps are indispensable for a molecule to participate in the formation of plasma polymer. Thus, the yield of deposition is thought to be controlled primarily by the activation (fragmentation) of molecular bonds. Although the detaileld understanding of this fragmentation process is

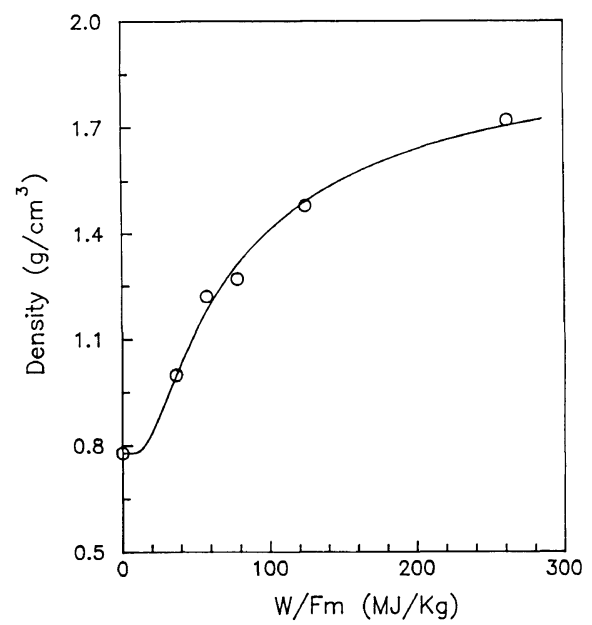

Figure 4. Effect of $W / F_{\mathrm{m}}$ on the density of HMDSIZ plasma polymer. an extremely difficult task due to the complexity of plasma reactions, ${ }^{1}$ a simplified model for that process is still required to explain the observed deposition rates. We postulate the fragmentation (activation) process to be a kind of "activated process" by the specific energy $W / F_{\mathrm{m}}$. Then, the yield of deposition $\left(D R_{\mathrm{m}} / F_{\mathrm{m}}\right)$ can be expressed as shown in eq 1 by the quasi-Arrhenius manner, where the specific energy $W / F_{\mathrm{m}}$ replaces the thermal energy $R T$ of Arrhenius equation.

$$
D R_{\mathrm{m}} / F_{\mathrm{m}}=C \times \exp \left(-E_{\mathrm{a}} /\left(W / F_{\mathrm{m}}\right)\right)
$$

where, $E_{\mathrm{a}}$, apparent activation energy. $C$, constant which is determined by the geometry of plasma reactor

Experimentally evaluated deposition rates of HMDSIZ plasma polymer are shown in Faigures 5 and $6 . \log \left(D R_{\mathrm{m}} / F_{\mathrm{m}}\right)$ was plotted against $W / F_{\mathrm{m}}$ in Figure 5 according to the mathematical form of eq 1 , and $D R_{\mathrm{m}}$ was plotted against $F_{\mathrm{m}}$ at four $W$ levels in Figure 6 . The lines in Figures 5 and 6 were drawn using the eq 1 with $C$ and $E_{\mathrm{a}}$ values obtained by the non-linear regression analysis ${ }^{37}$ of data points $\left(C=1.579 \times 10^{-4} \mathrm{~cm}^{-2}, \quad E_{\mathrm{a}}=40.79 \mathrm{MJ} \mathrm{kg}^{-1}\right)$.

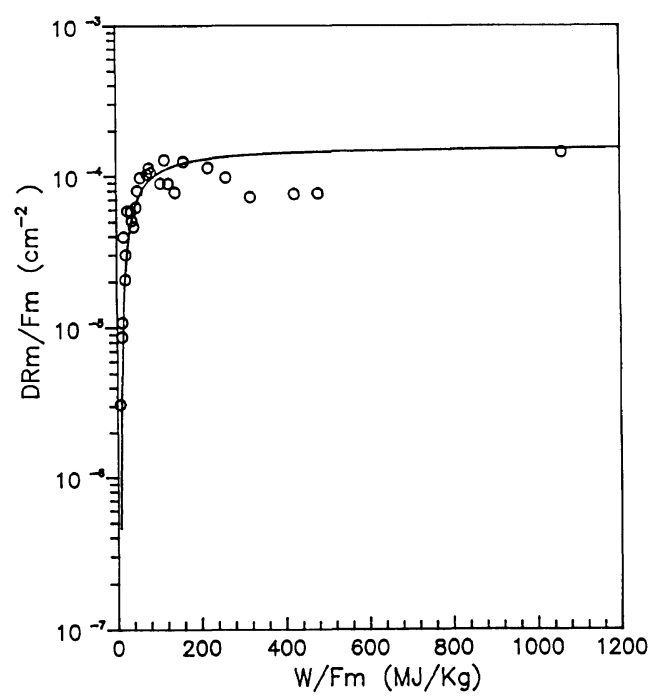

Figure 5. Yield of deposition $\left(D R_{\mathrm{m}} / F_{\mathrm{m}}\right)$ vs. specific energy per mass $\left(W / F_{\mathrm{m}}\right)$ plot for the plasma polymerization of HMDSIZ. 


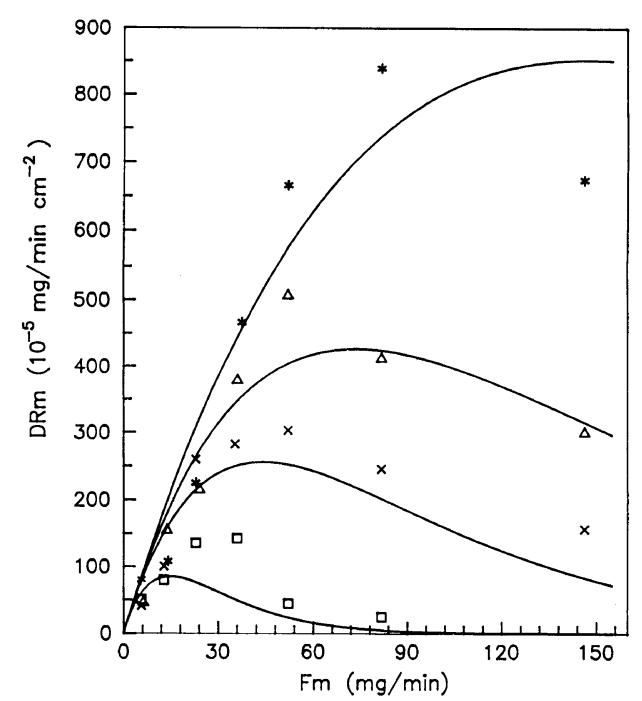

Figure 6. Deposition rate $\left(D R_{\mathrm{m}}\right)$ vs. mass flow rate $\left(F_{\mathrm{m}}\right)$ plot for the plasma polymerization of HMDSIZ: discharge power of $(\square) 10 ;(\times) 30 ;(\triangle) 50 ;(*) 100$ watts.

Although there exists some scatter in the data points, the lines seem to represent the proper relationship of $D R_{\mathrm{m}} / F_{\mathrm{m}}$ against $W / F_{\mathrm{m}}$ in Figure 5 and $D R_{\mathrm{m}}$ against $F_{\mathrm{m}}$ in Figure 6 . The same deposition kinetics conforming to the eq 1 were also observed with tetramethylsilane and hexamethyldisiloxane monomer. ${ }^{38}$ Moreover, the relationship graphically shown in Figures 5 and 6 is not different from the results reported by other investigators using various monomers. ${ }^{1}$ These facts altogether support our proposed eq 1 and the postulated model of plasma polymerization.

\section{CONCLUSIONS}

From the effects of operational parameters $W$ and $F_{\mathrm{m}}$ on the plasma polymerization of HMDSIZ, it was confirmed that the specific energy per mass $\left(W / F_{\mathrm{m}}\right)$ is a unique parameter which controls the chemical structure, density, and yield of deposition $\left(D R_{\mathrm{m}} / F_{\mathrm{m}}\right)$ of plasma polymer. Specifically, it was found that the $D R_{\mathrm{m}}$ of HMDSIZ plasma polymer could be described properly by the quasi-Arrhenius equation: $D R_{\mathrm{m}} / F_{\mathrm{m}}=C \times \exp \left(-E_{\mathrm{a}} /\left(W / F_{\mathrm{m}}\right)\right)$.

\section{REFERENCES}

1. H. Yasuda, "Plasma Polymerization," Academic Press, New York, 1985.

2. J. R. Hollahan, "Techniques and Application of Plasma Chemistry," Wiley-Interscience Publication, New York, 1974.

3. A. N. Mearns, Thin Solid Films, 3, 201 (1969).

4. S. Takeda, Jpn. J. Appl. Phys., 20, 1219 (1981).

5. Y. Segui, A. Bui, and H. Carchano, J. Appl. Phys., 47, 140 (1976).

6. D. Sanchez, M. Carchano, and A. Bui, J. Appl. Phys., 45, 1233 (1974).

7. K. Doblhofer and I. Eiselt, Thin Solid Films, 118, 181 (1984).

8. S. Morita, S. Hattori, M. Ieda, J. Tamano, and M. Yamada, Kobunshi Ronbunshu, 38, 657 (1981).

9. G. Akovali, J. Appl. Polym. Sci., 32, 4027 (1986).

10. N. J. Mazzeo, K. Y. Ahn, V. B. Jipson, and H. N. Lynt, Thin Solid Films, 108, 365 (1983).

11. P. K. Tien, G. Smolinsky, and R. J. Martin, Appl. Optics, 11, 637 (1972).

12. Y. Osada, A. Mizumoto, and H. Tsuruta, $J$. Macromol. Sci.-Chem., A24, 403 (1987).

13. P. V. Hinman, A. T. Bell, and M. Shen, J. Appl. Polym. Sci., 23, 3651 (1979).

14. T. Shimomura, M. Hirakawa, I. Murase, M. Sasaki, and T. Sano, J. Appl. Polym. Sci., Appl. Polym. Symp., 38, 173 (1984).

15. D. L. Cho and H. Yasuda, Proceedings of the ACS Division of Polymeric Materials, Vol. 57, 1987, p 599.

16. H. Yasuda and M. Gazicki, Biomaterials, 3, 68 (1982).

17. N. Inagaki, S. Kondo, M. Hirata, and $\mathrm{H}$. Urushibata, J. Appl. Polym. Sci., 30, 3385 (1985).

18. P. D. Buzzard, D. S. Soong, and A. T. Bell, J. Appl. Polym. Sci., 27, 3965 (1982).

19. N. Nakajima, A. T. Bell, and M. Shen, J. Appl. Polym. Sci., 23, 2627 (1979).

20. H. Yasuda, J. Polym. Sci., Macromol. Rev., 16, 199 (1981).

21. H. Yasuda and T. Hirotsu, J. Polym. Sci.-Chem., 16, 743 (1978).

22. H.-U. Poll, M. Artz, and K.-H. Wickleder, Eur. Polym. J., 12, 505 (1976).

23. D. K. Lam, R. F. Baddour, and A. F. Stancell, J. Macromol. Sci.-Chem., A10, 421 (1976).

24. A. T. Bell, J. Macromol. Sci.-Chem., A10, 369 (1976).

25. L. F. Thompson and K. G. Mayhan, J. Appl. Polym. Sci., 16, 2317 (1972).

26. R. G. Greenler, J. Chem. Phys., 44, 310 (1966).

27. N. Inagaki, K. S. Chen, N. Kadonome, and K. Katsuura, Kobunshi Ronbunshu, 38, 665 (1981).

28. R. Szeto and D. W. Hess, J. Appl. Phys., 52, 903 (1981).

29. Y. Osada and M. Takase, J. Polym. Sci.-Chem., 23, 
2425 (1985).

30. C. N. R. Rao, "Chemical Application of IR Spectroscopy," Academic Press, New York, N. Y., 1963.

31. A. M. Wrobel, J. E. Klemberg, M. R. Wertheimer, and H. P. Schreiber, J. Macromol. Sci.-Chem., A15, 197 (1981).

32. E. D. Lipp, Appl. Spectroscopy, 40, 1009 (1986).

33. N. Inagaki and H. Hirai, J. Polym. Sci.-Chem., 24, 595 (1986).
34. A. M. Wrobel, J. Macromol. Sci.-Chem., A22, 1089 (1985).

35. J. Mort and F. Jansen, "Plasma Deposited Thin Films," CRC Press, Boca Raton, 1986.

36. M. Gazicki and H. Yasuda, J. Appl. Polym. Sci., Appl. Polym. Symp., 38, 35 (1984).

37. J. Kuester and J. Mize, "Optimization Techniques with Fortran," John Wiley \& Sons, New York, N. Y., 1973, pp 251-256.

38. S. Y. Park, Ph.D thesis, Seoul National Univ., 1988. 